\title{
28 Resarach Soure \\ Learning from COVID-19: a systems approach for public health governance
}

Jieling Liu ( $\square$ jielingliu@campus.ul.pt )

University of Lisbon, Indiana University https://orcid.org/0000-0002-7930-9099

Yurong Wu

Sun Yat-Sen University

Cunrui Huang

Sun Yat-Sen University

Report

Keywords: COVID-19, pandemic response, public health, systems approach

Posted Date: November 9th, 2020

DOl: https://doi.org/10.21203/rs.3.rs-64888/v2

License: (1) This work is licensed under a Creative Commons Attribution 4.0 International License.

Read Full License 


\section{Abstract}

The COVID-19 rapidly evolved into a global pandemic. Countries have taken measures widely to prevent and control the epidemic. China for example, has control the spread effectively, while many countries are still striving to cope with the increasing COVID-19 confirmed cases. The epidemic revealed serious problems of public health governance in many countries with long lasting social and economic consequences. This commentary reviews the pandemic response measures in five selected countries: China, Italy, the United States, Brazil and India. Building on critical reflections on the problems incurred in each country's pandemic responses, we provide a theoretical framework to reconceptualize public health as multiple types of economic goods. We further couple this reconceptualization with a systems approach to public health and wellbeing to offer new thinking on health governance. Finally, we propose suggestions for better, preventative and comprehensive epidemic prevention and health governance in an increasing urban future.

\section{Introduction}

The COVID-19 pandemic has shaken many families and lives throughout the world. On 30 January, the WHO declared the Chinese outbreak of COVID-19 to be a Public Health Emergency of International Concern (PHEIC) posing a high risk to countries with vulnerable health systems. ${ }^{[1]}$ The COVID-19 subsequently has spread rapidly worldwide and the number of cases and deaths continue to rise every day. By August 7, 2020, the number of total confirmed cases has closed to 20 million, and the number of total deaths also has reached half milllion across 212 countries. ${ }^{[2,3]}$

To control the spread of COVID-19, the Chinese government was the first to raise national public health response to the highest state of emergency ${ }^{[4]}$ and carried out extreme control strategies, sunch as the lockdown of the entire Wuhan city and strict qurantine measures. Looking back, the early quarantine strategy was extremely important for controlling the pandemic. Delayed responses will drastically increase the spread of COVID-19 and prolong the time of socio-economic recovery. ${ }^{[5]}$

Historically, a quarantine refers broadly to measures of home control of infections and includes wearing masks in the presence of other household members, separate use of utensils and other home appliances and space. These measures have been effective in responding to public health emergencies and infectious diseases. ${ }^{[6][7]}$ Recent uses of the quarantine approach in China include the control of the Severe Acute Respiratory Syndrome (SARS) in $2003^{[8]}$ and the Influenza A virus subtype (H1N1) pandemic in 2009. ${ }^{[9]}$ The quarantine approach has been practiced in other countries too in recent years. During the Ebola outbreak in Western Africa in 2014, people who had been in contact with patients were order to stay in their homes or special facilities for 21 days. ${ }^{[10]}$

However, quarantine is far from a panacea and it has many limits. ${ }^{[11]}$ From the public health governance perspective, the COVID pandemic has evolved into a governance dilemma for all levels of governments worldwide, testing their emergency coping capacity in today's increasingly urban society. It is worth 
asking: what can we learn from the lessons and experience coping with COVID-19, and what is needed for better public health governance? We aim to address these questions in this commentary. First, we offer a comparative review of the pandemic response measures among five selected counrties, reflecting on the problems incurred in each country's pandemic response. Second, we provide a theoretical framework of public health as multiple types of economic goods and services. We further couple the theoretical framework with a systems approach to public health and wellbeing as inspiration for new governance. Lastly, we propose suggestions for better, preventative and comprehensive epidemic prevention and public health governance.

\section{Responses, Problems And Experience In Different Hard-hit Countries}

To get a more accurate picture of the global pandemic response, we chose five countries - China, Italy, the United States, India and Brazil, to represent the worst-hit countries in Asia, Europe, North America, and emerging developing economies respectively. In addition to geographical representations, China, India, and Brazil in particular can offer lessons learned in coping with COVID among the large or dense population; whilst the United States and Italy can offer lessons learned in treating data privacy and elderly population.

Figure 1 shows a comparison between daily new confirmed COVID-19 cases V.S. daily new confirmed COVID-19 deaths among these countries. Italy and the United States were particularly hard hit. Even though all three countries have taken similar quarantine measures ranging from two to four or even more weeks, the rapid increase in the number of new contractions has been common in Brazil, the United States, and Italy. While the number of COVID-19 deaths remain high in the United States, Brazil, and India, Italy has had a drastic increase since the ralatively peaceful summer monthshas.

COVID-19 broke out in Wuhan city, China and spread rapidly across the country at the beginning of 2020 . Wuhan has been known as the "Chicago of China" for its role as a business hub throughout the nation's modern history with high population mobility. Aggravated by high mobility, the coronavirus spreaded from Wuhan to the rest of Mainland China within one month. ${ }^{[13]}$ Since Professor Zhong Nanshan, distinguished Chinese pulmonologist confirmed the human-to-human transmissibility of 2019-nCoV on January $21,{ }^{[14]}$ the national government has decisively a quarantine for Wuhan, with additional measures in: case detection with immediate isolation, contact tracing, and medical observation, increase in medical resource supply (transforming stadiums, hotels and schools into hospitals for centralized quarantine). ${ }^{[15]}$ [16][17] By March 18, the government reported zero new confirmed cases in Hubei Province. ${ }^{[18]}$ Since then, China has entered a phase referred to as normalized prevention and control. Yet COVID-19 has been a recurrent risk. On June 13, 36 confirmed new COVID cases emerged at the Xinfadi wholesale market in Beijing. For this regional outbreak, the local government responded swiftly with large-scale PCR tests and epidemiological investigation. China's current localized approach to pandemic control has showcased the the principle of timely detection, rapid disposal, precise control and effective treatment. 
Italy was the first developed country in which COVID-19 reached a major outbreak outside of China. In Italy, unfortunately there was a long gap between the first diagnose confirmed on January 31 to the first death reported on February 21, which gave the coronavirus the chance to transmit widely across the country. On March 8, the Italian Government implemented extraordinary measures to limit COVID transmission, including travel restrictions in the Lombardy region, as well as a quasi nation-wide lockdown. ${ }^{[19]}$ Additional efforts include the closure of schools, universities and many services including theaters, cinemas, and pubs. Public transportation was highly restricted, all sports events and religious ceremonies were suspended. ${ }^{[20,21]}$ Italy experienced the month of March with appallingly high fatality. The deadliest day from Coronavirus was March 27, in which 969 people died. After a prolonged and persistent quarantine, The Italian health system became relatively in control of COVID-19 since May. By June 2, Italy reopened its borders to tourists. At the moment (end of October), a sharp increase of new confirmed cases has again been recorded in the country.

The Unite States, Brazil and India became the top three countries respectively for having the highest confirmed COVID-19 cases as of August 7. The United States is worst hit by the second wave of COVID contractions. The first case of COVID-19 was announced on January 20, 2020, in Washington State. The state of New York quickly became the epicenter with the majority of cases and deaths reported in New York City. ${ }^{[22]}$ The country suspended all entry of immigrants and non-immigrants to high-risk zones and set up quarantine stations 18 major ports of entry, hoping to halt the spread of the virus. ${ }^{[23,24]}$ By April 11, The United States surpassed Italy and became the country with the highest number of confirmed COVID deaths in the world. As of August 7, The United States has exceeded 160,000 coronavirus deaths as more than 60,000 new cases are detected on this day alone across more than 12 states. Compared to other countries, the United States has taken fewer countermeasures: city/region-wide lockdown in most states was imposed only for March and April, increase in medical resource supply in badly-hit states was insufficient for the demand, and event suspension did not stop people from going onto the streets for protests against COVID measures or for racial justice purposes. One of the challenges for the United States is that the decentralized decision-making system resulted in many states undervaluing the risks for economic motives, hence made a minimal intervention to control the pandemic.

Brazil, where the first case of COVID-19 registered in Latin America, implemented the social distancing measure such as remote working for vulnerable civil servants and at-risk groups. ${ }^{[25]}$ That first patient, who had mild symptoms, was given standardized care recommended by the epidemiological surveillance authorities and told to self-isolate at home while contacts were investigated among family members. ${ }^{\text {[25] }}$ Another emerging developing country, India, confirmed its first case in the country on January 30 and similar like in Italy, the first coronavirus death was recorded much later, on March 12. With Italy as an alarming precedent reference, India was quick to close its international borders and enforce an immediate lockdown. ${ }^{[26]}$

Reviewing the COVID transmission experiences and responses in these five countries, it's fair to say that the COVID-19 pandemic has revealed many problems of public health governmence in these countries. In 
the early stage of the pandemic, the local government of Wuhan lacked the capacity and transparency in coping with the pandemic, which resulted in questions and doubts from the public. The lack of credible information prompted many citizens to panic and hoard daily goods. In addition, emergency medical supplies in all these countries were insufficient. ${ }^{[27]}$ The abrupt quarantine also particularly worsened the financial situations for large groups of low-income population, such as urban migrant workers, refugees in war-torn zones, and small medium-sized enterprises. Though the health system in Italy is highly regarded and has 3.2 hospital beds per 1000 people (as compared with 2.8 in the United States, see Table 1 ), it has been extremely challenging to take in all the critically ill patients simultaneously. ${ }^{[30]}$ In the most affected regions, the National Healthcare Service was close to collapsing. ${ }^{[31]}$ India was quick to act but without an adequate health system in place. ${ }^{[32]}$ Owing to the lack of accurate data collection and tracking as well as test equipment, India faced an even more complicated challenge of controlling the pandemic. What's worse, in Brazil, false messages from political leaders and inadequate health system delayed in measures needed to contain the virus. ${ }^{[33]}$ 


\begin{tabular}{|c|c|c|c|c|c|c|c|c|c|c|}
\hline \multirow{3}{*}{$\begin{array}{c}\text { End of month } \\
2020 \\
\text { January }\end{array}$} & \multicolumn{10}{|c|}{ Total cases (left, no background) V.S. total death (right, grey background) } \\
\hline & \multicolumn{2}{|c|}{ China } & \multicolumn{2}{|c|}{ Italy } & \multicolumn{2}{|c|}{ United States } & \multicolumn{2}{|c|}{ Brazil } & \multicolumn{2}{|c|}{ India } \\
\hline & $9,714.0$ & 213.0 & 3.0 & & 6.0 & & & & 1.0 & \\
\hline February & $79,355.0$ & $2,837.0$ & 888.0 & 21.0 & 66.0 & & 1.0 & & 3.0 & \\
\hline March & $82,241.0$ & $3,309.0$ & $101,739.0$ & $11,591.0$ & $164,620.0$ & $3,170.0$ & $4,579.0$ & 159.0 & $1,251.0$ & 32.0 \\
\hline April & $83,944.0$ & $4,637.0$ & $203,591.0$ & $27,682.0$ & $1,039,909.0$ & $60,966.0$ & $78,162.0$ & $5,466.0$ & $33,050.0$ & $1,074.0$ \\
\hline May & $84,128.0$ & $4,638.0$ & $232,664.0$ & $33,340.0$ & $1,770,384.0$ & $103,781.0$ & $498,440.0$ & $28,834.0$ & $182,143.0$ & $5,164.0$ \\
\hline June & $84,780.0$ & $4,641.0$ & $240,436.0$ & $34,744.0$ & $2,590,552.0$ & $126,140.0$ & $1,368,195.0$ & $58,314.0$ & $566,840.0$ & $16,893.0$ \\
\hline July & $87,489.0$ & $4,659.0$ & $247,158.0$ & $35,132.0$ & $4,495,014.0$ & $152,070.0$ & $2,610,102.0$ & $91,263.0$ & $1,638,870.0$ & $35,747.0$ \\
\hline August & $89,895.0$ & $4,722.0$ & $268,218.0$ & $35,477.0$ & $5,997,163.0$ & $183,069.0$ & $3,862,311.0$ & $120,828.0$ & $3,621,245.0$ & $64,469.0$ \\
\hline September & $90,528.0$ & $4,739.0$ & $313,011.0$ & $35,875.0$ & $7,191,061.0$ & $205,998.0$ & $4,777,522.0$ & $142,921.0$ & $6,225,763.0$ & $97,497.0$ \\
\hline Population density & 147. & & 205.8 & & 35. & & 25 . & & 450. & \\
\hline Median age & 38. & & 47. & & 38 & & 33 & & 28. & \\
\hline GDP per capita & 15,308 & 8.712 & 35,220 & 0.084 & 54,22 & 5.446 & 14,10 & 3.452 & 6,426 & 674 \\
\hline $\begin{array}{c}\text { Hospital beds per } \\
\text { thousand }\end{array}$ & 4.3 & & 3.1 & & 2 . & & 2. & & 0.5 & \\
\hline Life expectancy & 76. & & 83.5 & & 78 & & 75. & & 69. & \\
\hline Countermeasures & $\mathrm{ABCDI}$ & EFGH & $\mathrm{ABCE}$ & EGH & $\mathrm{AF}$ & & $\mathrm{AE}$ & & $\mathrm{AEF}$ & \\
\hline
\end{tabular}

Table 1: COVID Country profile. Data source: European Centre for Disease Prevention and Control (ECDC), Oxford Martin School, and the Global Change Data Lab.

* Population density: Number of people divided by land area, measured in square kilometers, most recent year available from World Bank - World Development Indicators, sourced from Food and Agriculture Organization and World Bank estimates. 

a. Mandated city/region-wide quarantine/lock-down/curfew
b. Case detection with immediate isolation
c. Contact tracing
d. Medical observation
e. Increase in medical resource supply (equipments, temporary hospitals, professionals, etc)
f. Centralized quarantine
g. Travel restriction
h. Event suspension

In a nutshell, all these five countries have been badly hit, also owing to high population mobility and economic volume. There are some common challenges faced by these five countries, including a shortage of medical supplies, difficulties in restricting travel. Contact tracing has been a common challenge too. In countries like India and Brazil, contact tracing has been a common challenge due to insufficient technological access, whilst in the United States and Italy, it has been due to the concern of privacy. Quarantine measures in these five countries were similar but differentiated regarding time and population coverage. Besides, there are also unique challenges faced by specific countries, for instance, for the United States and Italy, centralized quarantine is not only a concern of public expenditure but also is considered an infringement of certain civil rights. While it might be valid universally, but particularly for China, India, and Brazil, quarantine and suspension of activities have been economically devastating for the low-income population.

As a result, the outcome of COVID-19 control in these five countries was distinctive from one another. The pandemic has returned as a second wave as countries across the world reopened. The global urbanization trend is bringing people physically closer and more connected to each other than ever. The increasing urban density and speed of social and economic activities have exacerbated the spread of COVID-19 which is endangering particularly emerging, dense urban areas with less developed medical prevention and control mechanisms as well as with a large ageing population.

Besides, the industrilised economy driven urbanization has agravated global warming and consequencial impacts, even though is has increased many people income and life quality. The current consumption habbit of industrialized agricultural products as well wild animal consumption imply that we will continue to be exposed to viruses from nature in the foreseeable future. For now, the majority of the human population is still susceptible to COVID-19, which means authorities still need to be vigilant and take countermeasures to protect their citizens before an effective vaccine is developed. Thus, it is necessary to reflect on the current public health governance and propose new approaches to improve the current system. 


\section{Theoretical Reframing Of Public Health Resources For Better Governance}

From a public governance perspective, the WHO defines health as a resource for everyday life, a necessary condition for socio-economic development and a fundamental human right.[1] Governments are expected to intervene and maintain public health by providing medical infrastructure and services using public resources (such as tax budgets), in addition to necessary supplementary means to health provision by the private sector. This is due to the defect of private-sector health provision. While it might be efficient in meeting some aspects of individual health needs, such as the allocation of food, privatesector health provision creates nuisance effects. For example, private health care may create inequalities in health access due to individuals having varied financial limits. Hence, health services cannot be primarily treated as private goods like they currently are in many developed states.

Public health resources or services are determined by social, environmental and technological features which could be public, private, club goods or even common-pool resources (Table 2). For example, food and common vaccines are ideally public goods as they are basic conditions for health. No one should be excluded from these basic conditions, nor should anyone's access to food and common vaccines be an obstacle for others to obtain the same. Products like toothbrushes and facial masks are necessarily exclusive and rivalry for health purpose, they, therefore, are private goods. Premium health maintenance and high-end wellbeing products are often club goods which allow non-rivalry and exclusive access depending on consumers' willingness to pay. Urban green spaces are known to have multiple health benefits, they are not exclusive to any individuals, but some users entering a green space could result in less available space or facilities for other potential users. Therefore, urban green spaces, for example, are often considered common-pool resources.

\begin{tabular}{|lll|}
\hline $\begin{array}{l}\text { Table 2: } \\
\text { Typology of } \\
\text { public health } \\
\text { resources }\end{array}$ & Excludable & Non-excludable \\
\hline Rivalry & Private goods & Common-pool goods \\
& $\begin{array}{l}\text { e.g., toothbrushes, facial masks, retail } \\
\text { and prescribed drugs }\end{array}$ & $\begin{array}{l}\text { e.g., urban green spaces, medicinal } \\
\text { plants, health centers, public hospital } \\
\text { beds and equipment }\end{array}$ \\
\hline Non-rivalry & $\begin{array}{l}\text { Club goods } \\
\text { e.g., Premium health maintenance and } \\
\text { high-end wellbeing products, tailored } \\
\text { personal care, private parks, swim clubs, }\end{array}$ & $\begin{array}{l}\text { Public goods } \\
\text { e.g., free healthcare, health norms, } \\
\text { common health culture, food and } \\
\text { common vaccines, healthy living } \\
\text { environment }\end{array}$ \\
\hline
\end{tabular}

Therefore, public health governance requires dealing with the entire range of goods and services which a city provides. Public health is an outcome of many interacting social, environmental and technological determinants in the city, such as transportation, housing, education, food and nutrition, the economy and 
income opportunities, green spaces and social cohesion. One single form of governance to address all types of public health goods and services is insufficient for managing health; rather, it becomes malfunctioning when public health emergencies appear in the first instance. Accordingly, health governance needs to use the entire bandwidth of governance types: market or private sector, the government, and communities. A systems approach is a suitable approach for public health governance, as it is about the management of all the goods and services, which, by their interactions and functioning, constitute public health.

Apart from applying different governance types to the appropriate type of good or service and at the right scale, a systems approach to public health governance consists of (1) an improved understanding of the complex interactions and functioning of one or more determinants of public health, including possible causes for an infectious disease outbreak, (2) the active participation and collective action of stakeholders in the co-creation, management and knowledge of public health. As such, a systems approach constitutes a multi-level collective learning cycle. With each cycle, the knowledge and management of certain public health aspects can improve and contribute to advancing collective intelligence in society. Collective intelligence is an emergent property of (1) an improved data metabolism, which turns data into information and knowledge, (2) it consists of the transformation of knowledge into action, and (3) involves all stakeholders in a continuous learning process with multiple feedbacks. A systems approach is the precondition for collective intelligence to emerge.

In line with that understanding of public health and governance, the level of public health depends not only on the services which governments provide, but also on individual members of society to co-create and maintain it. The individual members of society need to recognize that it is within their responsibility to learn and participate in public health management. The Ottawa Charter for Health Promotion recognizes the need to enable people to have greater control over their health and well-being. ${ }^{\left[{ }^{34]}\right.}$ The Healthy China 2030 Agenda also emphasizes that people should be responsible for their health under the leadership of governments. ${ }^{[35]}$

[1] WHO. 2017. Human rights and health. Available at: https://www.who.int/news-room/fact-

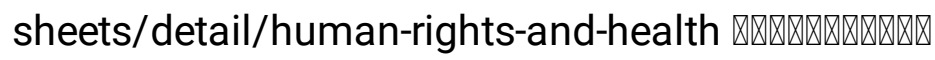

\section{Improving Public Health Governance In An Increasingly Urban Future}

Back to the experience and COVID-19 control responses of the five countries mentioned above, effective centralized coordination and rapid response to a public health emergency of a large population and economic scale is needed to be recognized and widely learnt among the international health management community. Besides, the rapid global spread of COVID-19 has shown that world governments, public health sectors and individual citizens by and large lack a precautionary mindset in public health management. A precautionary approach is better than the best emergency response, especially when human health is at stake. 
Drawing these lessons learned and the systems approach framework presented above, we thereby provide recommendations for better public health governance for national and local governments worldwide in an increasingly urban future. First, we recommend governments adopt a more polycentric public health governance approach with better regulation, information and multiple stakeholder participation. Governments not only need to take on the responsibility to act upon COVID-19 with the notion of health as a public good, but also need to accept their limitations. Governments need to cultivate a sense of shared responsibility and transparency between themselves, social enterprises and citizens, for building better social capital and maximizing the utility of private, club and common-pool health resources. Health promotion is not merely the responsibility of the health sector nor the vested interests of divided private enterprises. In this globalized world, the COVID-19 pandemic has quickly come to affect everyone. Individual citizens and enterprises, therefore, need to take on the responsibility to speak and act upon their best knowledge and potential for the health of their community. Governments need to facilitate public participation and private sector support in maintaining health with transparent and updated information.

Confronting an outbreak like COVID-19 requires trust and collaboration. "No single organization can deliver the wide range of services and systems needed for a truly global mechanism that prepares for and responds to outbreaks and emergencies," writes Margaret Chan, former director-general of the WHO, as she reflects on experiences from coping with Ebola. ${ }^{\left[{ }^{36]}\right.}$ Diversity in institutions and types of governance for health increases the effectiveness of preventive measures and societal resilience against a virus outbreak. Collective intelligence and societal resilience would reduce the high social and economic costs of drastic administrative decisions like the quarantine taken during an emergency.

Second, we recommend the public health system to move from responding to emergencies to long-term preparation with a precautionary mindset. This is due to the multiple attributes of public health resources (Table 2). For example, common-pool resources such as public hospital bed facilities and medical equipment require adequate public funding, planning, and long-term investment to set in place. Besides, due to the unpredictability and increased likelihood of future pandemics, it is necessary to prepare emergency medical supplies and medical professionals for the long term. A pandemic monitoring and early warning system based on health information contributed from bottom-up without constraints, would be critical to improving the preparedness of the public health system.

Additionally, recent studies have pointed out flawed understandings of the aerosol transmission route, the

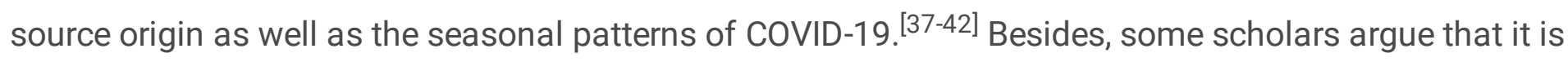
still too early to develop an accurate basic reproduction number $\left(R_{0}\right)$ estimate or to assess the dynamics of transmission. ${ }^{[43]} \mathrm{A}$ better scientific understanding of the emergence and transmission of the virus in the context of demographic, climate and environmental change is needed in the future, which can help governments make long-term preparation of public health system.

\section{Conclusion}


As we look to the future, pandemics are likely to become more frequent globally, unless we adopt a more systemic approach to public health governance. In a globally interconnected world, health concerns us all and getting its governance right is urgently needed. As the rising numbers of confirmed cases of COVID19 are showing, the world remains dangerously unprepared for a global pandemic. It is inappropriate to meet public health challenges by relying on the government or private sector alone. As social justice and equity are core foundations for health, it is critical to involve the people to engage in long-term health prevention and maintenance. In addition to emergency response, public health governance needs to reform by adopting a more systemic approach that is long-term, multi-stakeholder, multi-sectoral, organized around community health services, particularly in the context of global climate change, rapid urbanization, demographic and epidemiological changes.

\section{Abbreviations}

COVID-19: Coronavirus disease 2019

SARS: Severe Acute Rrespiratory Syndrome

WHO: World Health Organization

GDP: Gross Domestic Product

\section{Declarations}

Ethics approval and consent to participate: No approval is needed for this study.

Consent for publication: Not appicable

Availability of data and material: Data sharing not applicable to this article as no data-sets were generated or analyzed during the current study.

Competing interests: The authors declare that they have no competing interests.

Funding: Not applicable

Authors' contributions: $\mathrm{JL}$ drafted and revised the manuscript, $\mathrm{CH}$ and $\mathrm{YW}$ participated in revising the manuscript. All authors read and approved the final manuscript.

Acknowledgements: Not applicable

\section{References}

1. Catrin Sohrabi, Z.A., Niamh O'Neill, Mehdi Khan, Ahmed Kerwan, Ahmed Al-Jabir, Christos losifidis, Riaz Agha. World Health Organization declares global emergency: A review of the 2019 novel coronavirus (COVID-19) Int J Surg. 2020; doi:10.1016/j.ijsu.2020.02.034. 
2. WHO Coronavirus Disease (COVID-19) Dashboard. Organization, W.H. 2020. https://covid19.who.int/. Accessed 1 July 2020.

3. Johns Hopkins University of Medicine Coronavirus Research Center. 2020. https://coronavirus.jhu.edu/map.html. Accessed 5 May 2020.

4. Tian H, L.Y., Li Y, et al. An investigation of transmission control measures during the first 50 days of the COVID-19 epidemic in China Science. 2020; doi:10.1126/science.abb6105.

5. Qianqian Cui, Z.H., Yingke Li, Junmei Han, Zhidong Teng, Jing Qian. Dynamic variations of the COVID-19 disease at different quarantine strategies in Wuhan and mainland China J Infect Public Health 2020; doi:10.1016/j.jiph.2020.05.014.

6. Svoboda T, H.B., Shulman L, et al. Public health measures to control the spread of the severe acute respiratory syndrome during the outbreak in Toronto N Engl J Med 2004; doi:10.1056/NEJMoa032111.

7. Tognotti, E. Lessons from the history of quarantine, from plague to influenza A. Emerg Infect Dis 2013; doi:10.3201/eid1902.120312.

8. D L Reynolds, J.R.G., S L Deamond, M K Moran, W Gold, R Styra. Understanding, compliance and psychological impact of the SARS quarantine experience. Epidemiol Infect. 2008; doi:10.1017/S0950268807009156.

9. Chu CY, L.C., Zhang H, et al. Quarantine methods and prevention of secondary outbreak of pandemic (H1N1) 2009 Emerg Infect Dis. 2010; doi:10.3201/eid1608.091787.

10. Liu, J. Disease outbreak: Finish the fight against Ebola Nature. 2015; doi:10.1038/524027a.

11. Gian Franco Gensini, M.H.Y., Andrea A. Contia. The concept of quarantine in history: from plague to SARS. J Infect. 2004; doi:10.1016/j.jinf.2004.03.002.

12. Roser, M. Coronavirus pandemic - Country comparisons. Our World in Data. 2020. https://ourworldindata.org/coronavirus-country-comparisons. 'Accessed' August 12, 2020.

13. Prevention, C.C.f.D.C.a. The epidemiological characteristics of an out break of 2019 novel coronavirus disease (COVID-19) in China. Chinese Journal of Epidemiology. 2020; doi:10.3760/cma.j.issn.0254-6450.2020.02.003.

14. Xingguang Li, J.Z., Xiaomei Wang, Yi Li Potential of large "first generation" human-to-human transmission of 2019-nCoV. J Med Virol. 2020; doi: 10.1002/jmv.25693.

15. Can Hou, J.C., Yaqing Zhou, Lei Hua, Jinxia Yuan, Shu He, Yi Guo, Sheng Zhang, Qiaowei Jia, Chenhui Zhao, Jing Zhang, Guangxu Xu, Enzhi Jia. The effectiveness of quarantine of Wuhan city against the Corona Virus Disease 2019 (COVID-19): A well-mixed SEIR model analysis J Med Virol 2020; doi:10.1002/jmv.25827.

16. A Wilder-Smith, D.O.F. Isolation, quarantine, social distancing and community containment: pivotal role for old-style public health measures in the novel coronavirus (2019-nCoV) outbreak. J Travel Med. 2020; doi:10.1093/jtm/taaa020. 
17. Centralized isolation and treatment - Wuhan's latest measures to fight the epidemic. Agency, X.N. 2020. http://www.gov.cn/xinwen/2020-02/05/content_5474834.htm. Accessed 5 February 2020.

18. The novel coronavirus pneumonia epidemic situation by 18 March. China, N.P.C.o.t.P.s.P.o. 2020. http://www.nhc.gov.cn/xcs/yqtb/202003/e644c2fc18b4448db7ed4b30f68b91a6.shtml. Accessed 19 March 2020.

19. Andrea Remuzzi, G.R. COVID-19 and Italy: what next? . Lancet 2020; doi:10.1016/S01406736(20)30627-9.

20. Giorgio, A.D. COVID-19 is not just a flu. Learn from Italy and act now Travel Med Infect Dis 2020; doi:10.1016/j.tmaid.2020.101655.

21. Henrik Sjödin, A.W.-S., Sarah Osman, Zia Farooq, Joacim Rocklöv. Only strict quarantine measures can curb the coronavirus disease (COVID-19) outbreak in Italy, 2020 Euro Surveill 2020; doi:10.2807/1560-7917.ES.2020.25.13.2000280.

22. Muhammad Farhan Bashir, B.M., Bilal, Bushra Komal, Muhammad Adnan Bashir, Duojiao Tan, Madiha Bashir. Correlation between climate indicators and COVID-19 pandemic in New York, USA Sci Total Environ 2020; doi:10.1016/j.scitotenv.2020.138835.

23. Anita Patel, D.B.J., 2019-nCoV CDC Response Team. Initial Public Health Response and Interim Clinical Guidance for the 2019 Novel Coronavirus Outbreak - United States, December 31, 2019 February 4, 2020 MMWR Morb Mortal Wkly Rep 2020; doi:10.15585/mmwr.mm6905e1.

24. Proclamation on Suspension of Entry as Immigrants and Nonimmigrants of Persons Who Pose a Risk of Transmitting 2019 Novel Coronavirus. House, T.W. 2020.

https://www.whitehouse.gov/presidential-actions/proclamation-suspension-entry-immigrantsnonimmigrants-persons-pose-risk-transmitting-2019-novel-coronavirus/. Accessed 31 January 2020.

25. Aquino EML, S.I., Pescarini JM, et al. Social distancing measures to control the COVID-19 pandemic: potential impacts and challenges in Brazil Cien Saude Colet 2020; doi:10.1590/141381232020256.1.10502020.

26. Lancet, T. India under COVID-19 lockdown Lancet 2020; doi:10.1016/S0140-6736(20)30938-7.

27. Xu Wang, X.Z., Jiangjiang He Challenges to the system of reserve medical supplies for public health emergencies: reflections on the outbreak of the severe acute respiratory syndrome coronavirus 2 (SARS-CoV-2) epidemic in China Biosci Trends 2020; doi:10.5582/bst.2020.01043.

28. Maolin Liao, L.Z. The effect of novel coronavirus epidemic on the economic growth in China. Fujian Tribune. 2020;04:25-33.

29. Wu Tingting, Z.A. Novel coronavirus pneumonia's impact on China's economy and coping strategies. South China Finance. 2020;05:3-11.

30. Rosenbaum, L. Facing Covid-19 in Italy - Ethics, Logistics, and Therapeutics on the Epidemic's Front Line. N Engl J Med 2020; doi:10.1056/NEJMp2005492.

31. Armocida, B., et al. The Italian health system and the COVID-19 challenge. The Lancet Public Health. 2020; doi:10.1016/s2468-2667(20)30074-8. 
32. Baru, R.V. Health systems preparedness during COVID-19 pandemic: China and India Indian J Public Health 2020; doi:10.4103/ijph.IJPH_501_20.

33. Anna Cristina Calçada Carvalho, A.K. c. Rev Soc Bras Med Trop 2020; doi:10.1590/0037-8682-01992020.

34. Organization, W.H. Ottawa Charter for Health Promotion. Health \& Welfare Canada/canadian Public Health Association. 1986; doi:10.1093/heapro/1.4.405-a.

35. Xiaodong Tan, X.L., Haiyan Shao Commentary: Healthy China 2030: a vision for health care. Value in Health Regional Issues. 2017; doi:10.1016/j.vhri.2017.04.001.

36. Chan, M. Learning from Ebola: readiness for outbreaks and emergencies. Bull World Health Organ. 2015; doi:10.2471/BLT.15.165720.

37. Muhammad Adnan Shereen, S.K., Abeer Kazmi, Nadia Bashir, Rabeea Siddique. COVID-19 infection: Origin, transmission, and characteristics of human coronaviruses J Adv Res 2020; doi:10.1016/j.jare.2020.03.005.

38. Pengfei Sun, X.L., Chao Xu, Wenjuan Sun, Bo Pan. Understanding of COVID-19 based on current evidence. J Med Virol 2020; doi:10.1002/jmv.25722.

39. Kit San Yuen, Z.Y., Sin Yee Fung, Chiping Chan, Dongyan Jin. SARS-CoV-2 and COVID-19: The most important research questions. Cell Biosci 2020; doi:10.1186/s13578-020-00404-4.

40. Zi Yu Ge, L.Y., Jiajia Xia, Xiaohui Fu, Yanzhen Zhang Possible aerosol transmission of COVID-19 and special precautions in dentistry J Zhejiang Univ Sci B 2020; doi:10.1631/jzus.B2010010.

41. Mahesh Jayaweera, H.P., Buddhika Gunawardana, Jagath Manatunge. Transmission of COVID-19 virus by droplets and aerosols: A critical review on the unresolved dichotomy Environ Res 2020; doi:10.1016/j.envres.2020.109819.

42. George Kroumpouzos, M.G., Mohammad Jafferany, Torello Lotti, Roxanna Sadoughifar, Zuzanna Sitkowska, Mohamad Goldust COVID-19: A relationship to climate and environmental conditions? Dermatol Ther 2020; doi:10.1111/dth.13399.

43. Feng He, Y.D., Weina Li. Coronavirus disease 2019: What we know? . J Med Virol 2020; doi:10.1002/jmv.25766.

\section{Figures}


A.

Daily new confirmed COVID-19 cases

Shown is the rolling 7-day average. The number of confirmed cases is lower than the number of actual cases; the main reason for that is limited testing.

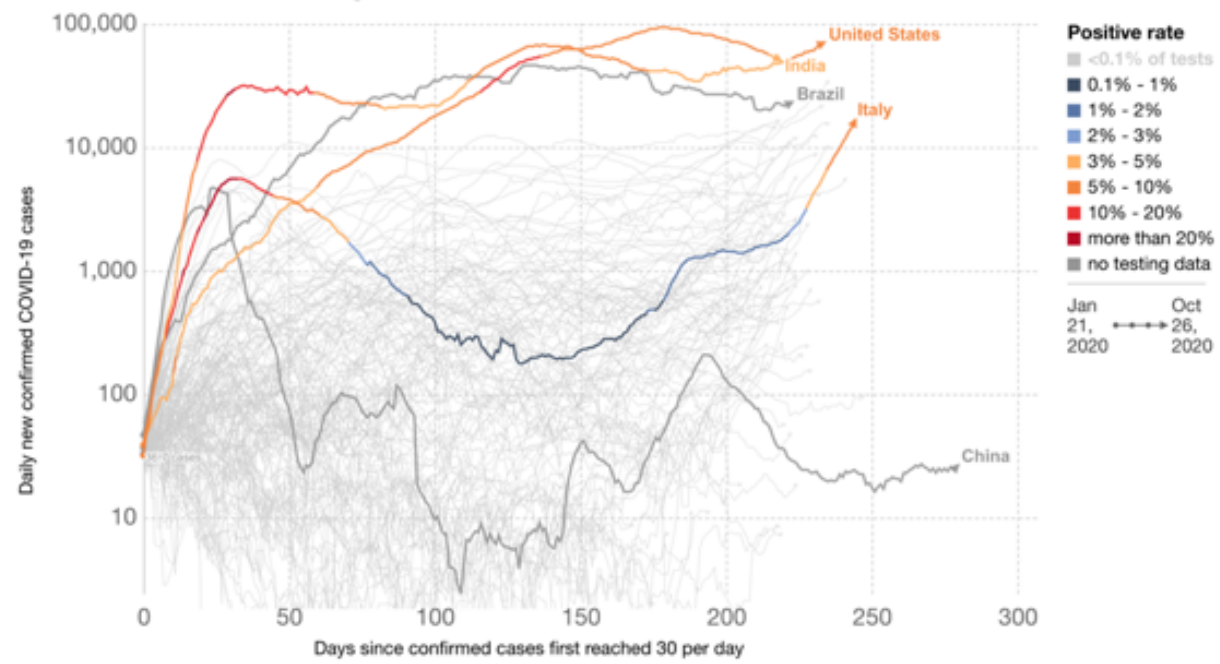

Source: European CDC - Situation Update Worldwide - Last updated 26 October, 10:35 (London time), Official data collated by Our World in Data
CC BY

B.

Daily new confirmed COVID-19 deaths

Shown is the rolling 7-day average. Limited testing and challenges in the attribution of the cause of death means that the number of confirmed deaths may not be an accurate count of the true number of deaths from COVID-19.

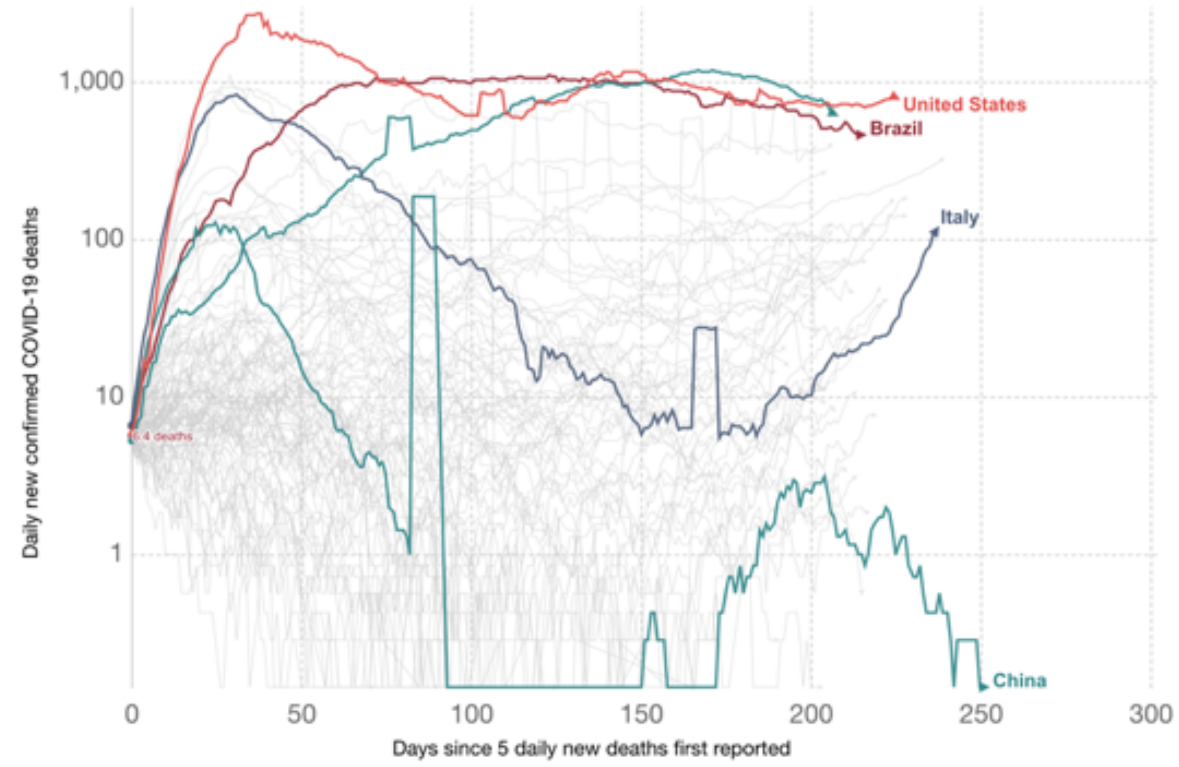

Source: European CDC - Situation Update Worldwide - Last updated 26 October, 10:35 (London time), Our World In Data

Continent IIt Airic

asia

- Europe

North America

South America

Jan

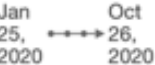

$2020 \quad 2020$

CCBY

\section{Figure 1}

Daily new confirmed COVID-19 cases (A) V.S. Daily new confirmed COVID-19 deaths (B). Source: Our World in Data/Roser, updated October 26, 2020[12] 